\title{
Análise dos Normativos de Contabilidade Internacional sobre Contabilização de Contratos de Parcerias Público-Privadas
}

Analyzing the International Accounting Guidelines for Contract Accounting of Public-Private Partnerships

Maria Elisabeth Moreira Carvalho Andrade

Mestranda em Controladoria e Contabilidade da Faculdade de Economia, Administração e Contabilidade de Ribeirão Preto FEA-RP - USP

Professora do Curso de Ciências Contábeis da Universidade de Uberaba e da Faculdade de Ciências Econômicas do Triângulo Mineiro

Endereço: Rua Independência, n 175, Bairro Parque das Américas

CEP: $38045-120$ - Uberaba/MG - Brasil

E-mail: mbethandrade@terra.com.br

Telefone: (34) 8843-1610

\section{Vinícius Aversari Martins}

Doutor em Controladoria e Contabilidade pela Universidade de São Paulo

Professor do Mestrado em Controladoria e Contabilidade da Faculdade de Economia, Administração e Contabilidade de Ribeirão Preto FEA-RP - USP

Endereço: Av. Bandeirantes, n॰3900, Bairro Monte Alegre

FEA-RP/USP - Bloco C - Sala 13

CEP: 14040-900 - Ribeirão Preto/SP - Brasil

E-mail: vinicius@usp.br

Telefone: (16) 3602-3943

Artigo recebido em janeiro de 2009. Passou por uma avaliação double blind review em agosto de 2009. Aceito em outubro de 2009 pela Editora Científica Sandra Rolim Ensslin. Artigo apresentado no III Encontro de Administração Pública e Gorvenança (EnAPG), 2008, Salvador, 2008. 


\title{
Resumo
}

O artigo trata da contabilização dos contratos de Parcerias Público-Privadas (PPPs), quando o objetivo do contrato é realizar e/ou operar infraestruturas (rodovias, distribuição de energia e de água, entre outros). Tais contratos geram fatos contábeis diversos, com características econômicas distintas, cujas explicações e interpretações dão-se à luz de teorias contábeis e econômicas. É realizada revisão conceitual sobre riscos dos contratos e análise dos normativos contábeis. Conclui-se que, apesar de a norma ter o objetivo de dirimir os conflitos advindos dos eventos econômicos do contrato de PPPs, ajustes deverão acontecer tendo em vista que a norma foi omissa quanto à mensuração dos riscos.

Palavras-chave: Parcerias Público-Privadas (PPP), Contabilidade Internacional, Riscos, IFRIC 12.

\begin{abstract}
This paper discusses contract accounting of public-private partnerships (PPPs) in contracts related to building and/or managing infrastructure (roads, energy and water distribution, among others). These contracts generate a number of accounting factors, with singular economic features that can be explained and interpreted based on accounting and economic theories. The study revises concepts in the area of contract risks and analyzes accounting guidelines. Although the purpose of the guidelines is to avert conflicts stemming from the economic events of the PPPs contracts, it is necessary to refine the guidelines, as they fail to address the issue of risk measurement.
\end{abstract}

Key words: Public-Private Partnerships (PPPs), International Accounting, Risks, IFRIC 12.

\section{Introdução}

A Contabilidade no Brasil está passando por profundas modificações com a sanção da Lei n. 11.638/07, que veio alterar inúmeros aspectos da Lei das Sociedades Anônimas, sendo um dos seus objetivos a convergência com as normas internacionais, conforme dispõe o art. $177, \S 5^{\circ 1}$. Dada a relevância do assunto, é importante se contextualizar o processo de harmonização contábil, para então tratar das futuras contabilizações das Parcerias Público-Privadas (PPPs), pois atualmente estão se concretizando os primeiros contratos de PPPs, os quais necessitarão de aclaramentos contábeis. Tais contratos implicam eventos e fatos contábeis diversos, com características econômicas distintas, que são fundamentadas em teorias que procuram explicar esses fenômenos. Como ainda não é possível uma análise empírica abrangente, devido à regulamentação ter entrado em vigor no início de 2008, estudos futuros precisam ser realizados para subsidiar o desenvolvimento normativo e prático da Contabilidade desses tipos de contratos.

Dado o contexto atual, o objetivo deste artigo é analisar criticamente os normativos sobre as contabilizações das PPPs (tendo por base a IFRIC $12^{2}$ ) à luz das teorias de contratos, regulação, agência e contábil, buscando esclarecer quais são os aspectos positivos e negativos quando da adoção desse normativo para elaboração e divulgação das demonstrações contábeis dos parceiros privados das PPPs. 
Nas normas internacionais de Contabilidade, a IFRIC 12 (Service Concession Arrangements) é o normativo direcionado para contratos de concessões de serviços. Orienta os operadores dos serviços de concessão na contabilização dos contratos celebrados, estabelecendo princípios gerais sobre o reconhecimento e mensuração dos ativos e passivos, receitas e despesas, decorrentes do contrato que envolve esse tipo de prestação de serviço.

Cabe um comentário sobre o IFRIC e suas normas para o contexto deste artigo.

Interpretações contábeis provavelmente terão uma maior importância nos próximos anos, quando entidades na Austrália, na Europa, Nova Zelândia e em outros países vão para convergência à IFRS. Isto é importante para os países que nunca tiveram um grupo para resolver questões urgentes ou um comitê de interpretações. É também importante para os países que têm os comitês de interpretação entenderem o processo IFRIC ${ }^{3}$ para se posicionarem no mundo do $I A S B$. Por outro lado, revisões recentes e alterações dos processos do IFRIC indicam que as interpretações do IFRIC é um processo evolutivo ${ }^{4}$ (BRADBURY, 2007, p. 120).

Sendo as interpretações do $I A S B^{5}$ produtos de processo evolutivo, e altamente relevantes na normatização contábil internacional, põe-se a questão orientadora: A IFRIC 12, voltada para contratos de concessão de serviços, resolve adequadamente os possíveis problemas advindos da ausência de uma norma contábil na contabilização das PPPs no Brasil?

Para a elaboração deste artigo foi feita breve revisão bibliográfica sobre as teorias econômicas e contábeis atinentes às PPPs com a finalidade de melhor se entender as essências econômicas regulatórias das concessões e das parcerias público-privadas, objetivando-se a mensuração e evidenciação contábil desses contratos. Esse passeio bibliográfico, teórico e conceitual é relevante no contexto de mudança do paradigma contábil nacional pelo fato de o principal princípio orientador das normas internacionais ser a busca da evidenciação da essência econômica em detrimento da forma jurídica. Em se tratando de contratos de PPPs, regulados pelo poder concedente, essas análises tornam-se essenciais. Veja-se o comentário seguinte explorando um pouco mais esse contexto:

[...] se houver em algum momento, algum instrumento formal, mesmo que por lei ou apoiado em lei, que precise ser contabilizado e que se registrado conforme suas características formais, não represente bem a realidade, deve-se então abandonar, na contabilidade, a forma, e registrar-se a essência econômica dos fatos e atos escrituráveis (MARTINS, MARTINS e MARTINS, 2007, p. 15). 
Então, em um contrato de PPPs a ser contabilizado, deve-se demonstrar o real fato econômico na escrituração, proporcionando a confiabilidade da informação contábil, abandonando a natureza jurídica caso necessário.

\section{Um pouco sobre o IASB e a Contabilidade Internacional}

O IASB - International Accounting Standards Boards (2001), antigo IASC - International Accounting Standards Committee (1973), tem por objetivo desenvolver normas contábeis de qualidade em nível mundial, proporcionando informação transparente e de possível comparabilidade, possuindo como principal objetivo a interpretação econômica dos fatos, com a prevalência da essência sobre a forma sempre baseando nos principles oriented, ou seja, os pressupostos básicos e as características qualitativas das demonstrações contábeis para tentar minimizar os conflitos contábeis.

O órgão conta com a colaboração do International Reporting Interpretations Commitee - para a implantação dos padrões de Contabilidade Financeira, emitindo interpretações que são as IFRICs, órgão criado em março de 2002, pelos curadores do IASCF (International Accounting Standards Comittee Foundation) que veio substituir o anterior SIC. O IFRIC é o corpo interpretativo do $I A S B$, tendo como função, de acordo com o Handbook, revisar questões identificadas nos relatórios financeiros, não especificamente abordadas nas IFRSs, ou abordadas insatisfatoriamente, ou quando surgem interpretações conflitantes buscando um consenso ao tratamento adequado.

A emissão das IFRSs depende de um amplo processo conforme seu regimento, com consulta em nível internacional, sendo de responsabilidade do $I A S B$ as questões técnicas, incluindo a elaboração e emissão das IFRSs, bem como a aprovação final das interpretações elaboradas pelo IFRIC e desenvolvimento de agenda técnica. Os pronunciamentos técnicos do $I A S B$ não são de caráter obrigatório, mas a União Europeia, desde 2005, instituiu a obrigatoriedade de aplicação das IFRSs pelas companh $I A S$ abertas.

No Brasil, desde 2000, busca-se a aprovação do Projeto de Lei n. 3.741/00, que altera a Lei das Sociedades por Ações, que trata da convergência às normas internacionais. Em 2005, criou-se o Comitê de Pronunciamentos Contábeis - CPC, pela Resolução n. 1.055/05 com o objetivo de estudar, preparar e emitir Pronunciamentos Técnicos sobre procedimentos de Contabilidade, e a divulgação de informações dessa natureza para permitir a emissão de normas pela Comissão de Valores Mobiliários - CVM, visando à convergência da Contabilidade Brasileira aos padrões internacionais.

Sancionada a Lei n. 11.638, publicada em 28 de dezembro de 2007, entrando em vigor a partir de $1^{\circ}$ de janeiro de 2008, o Brasil acabou por ser inserido 
de forma definitiva no processo de convergência às normas internacionais de Contabilidade. E, por isso, também se justifica o fato de se entenderem quais as características contábeis a que os parceiros privados das PPPs serão submetidos, já que essa mudança toda é mais profunda do que se imagina; trata-se de uma mudança de paradigma da Contabilidade brasileira.

Após a contextualização das normas do $I A S B$ no Brasil, parte-se para o objeto deste estudo, a IFRIC 12, pois existe no IASB outro normativo (SIC 29) que trata exclusivamente da evidenciação, mas não da contabilização, de contratos de concessão. Na tentativa de cobrir a lacuna, devido à expansão mundial dessa nova modalidade de parceria, o IASB montou um grupo de trabalho com representantes da Austrália, França, Reino Unido e Espanha, países estes que haviam se manifestado sobre a necessidade de haver uma orientação sobre o assunto, sendo o resultado final a emissão da interpretação sobre o tema.

Portanto também se procura neste artigo contextualizar a contabilização dos contratos de PPPs à luz das teorias econômicas, para se ter primeiramente uma visão ampla dos seus efeitos econômicos para depois trazer os mesmos fatos para a Contabilidade propriamente dita.

\section{Contratos em regime de concessão, PPPs e Contabilidade}

É importante destacar que o termo Parcerias Público-Privadas é um conceito novo no Brasil, já que somente em 2004 foi aprovada a Lei n. 11.079/04 ${ }^{6}$, diferente da Lei n. 8.987/957, que trata apenas das concessões. Após a aprovação dessa lei, as PPPs começaram a tomar bastante destaque, tanto no meio empresarial quanto nos poderes concedentes ${ }^{8}$. Há que se diferenciar as PPPs da concessão regulamentada pela Lei n. 8.987/95, na qual, nesses contratos, o risco é totalmente suportado pelo parceiro privado que este recebe uma licença para explorar o serviço por um determinado período. Já nas PPPs, existe uma contraprestação pecuniária do parceiro público, proporcionando um compartilhamento de riscos.

Destaca-se ainda que os países que utilizam PPPs também possuem características diferentes, tenho em vista a cultura e as suas normas, conforme destacam Bonomi e Malvessi (2008, p. 85):

Em vários países, a definição de PPP abrange o que está regulado no Brasil como concessão e, em outros, está associada a um processo de licitação privatizado através de consultorias. É vista diferentemente em países onde a escolha de aplicações de recursos públicos é decidida em conselhos ou legislativos e onde os desembolsos são feitos através do poder executivo, exclusivamente. Assim, comparações internacionais devem ser vistas com cautela em função do país citado, de sua legislação e cultura. 
A concessão comum também é tratada como Project Finance, sendo de suma importância analisar as principais diferenças entre concessão e PPP. Para melhor entendimento, montou-se o quadro abaixo com as principais diferenças entre concessão e PPP.

Tabela 1: Principais diferenças entre concessão e PPP

\begin{tabular}{|l|l|}
\hline \multicolumn{1}{|c|}{ Concessão } & \multicolumn{1}{c|}{ PPP } \\
\hline - Fluxo de caixa previsível & - Fluxo de caixa mínimo ou até insuficiente \\
\hline - Equivalência entre os participantes (Direito Privado) & $\begin{array}{l}\text { - Impera o interesse público prevalecendo sobre o individual } \\
\text { (Direito Público) }\end{array}$ \\
\hline $\begin{array}{l}\text { - Ideal para serviços públicos com retorno viável e características de } \\
\text { monopólio (telecomunicações, energia etc.) }\end{array}$ & $\begin{array}{l}\text { - Risco Político de manutenção do fluxo de caixa contratado e } \\
\text { do marco regulatório }\end{array}$ \\
\hline - O maior risco está no fluxo de caixa comercial & - Compartilhamento de riscos entre o setor privado e o público \\
\hline
\end{tabular}

Fonte: Adaptado de Bonomi e Malvessi (2008).

A principal semelhança entre concessão e PPP é que não há transferência de ativos para o setor privado, como na privatização, e sim uma delegação para os parceiros públicos na gestão de ativos públicos. Até dezembro de 2007, Austrália, França, Reino Unido e Espanha contabilizavam os contratos de concessão e de parcerias público-privadas de acordo com várias normas do $I A S B$, não existindo um padrão ou interpretação específica quanto ao assunto, gerando algumas opiniões e contabilizações divergentes.

Esse tipo de regulação internacional vem justamente buscar consenso, como ocorreu na contabilização dos contratos sob o regime PPP. Vários posicionamentos foram favoráveis quanto a classificar as PPPs sob a égide da IAS 17 - Leasing, mas chegou-se à conclusão de que, por não existir em uma PPP, a transferência total de risco, não se deve classificar esse tipo de contrato de acordo com a $I A S 17$.

$\mathrm{Na}$ PPP, o poder concedente mantém o controle e a regulação (Parágrafo 5 da IFRIC 12), diferente do que ocorre com o leasing, motivo pelo qual a IFRIC 12 atende somente a contratos de PPP, os quais são divididos em dois tipos, assunto que será discorrido à frente.

Em novembro de 2006, o IASB emitiu a IFRIC 12, que entrou efetivamente em vigor em $1^{\circ}$ de janeiro de 2008, que trata da contabilização dos contratos, por parte do operador, celebrados entre as empresas (concessionár $I A S$ ou operadoras) e o Governo (poder concedente), surgindo uma complexidade de eventos contábeis. Esses contratos são muitas vezes descritos como build-operate-transfer (onde o empreendedor constrói, opera e transfere o bem ao poder concedente após determinado período), ou rehabilitate-operate-transfer ou 'public-to-private' service concession arrangement (contrato de serviço de concessão de PPP).

Não se pode confundir a PPP com uma privatização, pois naquela modali- 
dade os ativos são transferidos para o operador somente pelo tempo do contrato, e, ao seu término, eles retornam ao governo. Mesmo durante o período da parceria, o poder público pode exigir por meio de cláusulas contratuais que se cumpra um nível de performance sob um certo controle do setor público. Isso depende da elaboração bem feita de um arranjo.

Como o entusiasmo mundial com privatizações caiu, PPPs começou a "boom". Uma das razões que o governo gosta de PPPs é que elas proporcionam uma transferência temporária da maior parte dos benefícios da propriedade dos ativos a uma empresa privada, evitando assim a crítica daqueles que são contra a privatização. Ao mesmo tempo, porque alguns direitos de propriedade são transferidos, governo pode também afirmar que a participação do setor privado está avançada9 ${ }^{9}$ (ENGEL et al., 2007)

O Reino Unido é considerado o país pioneiro nesse tipo de investimento, surgindo ao final da década de 1990, que inicialmente chamou-se de PFI - Project Finance Initiative, e posteriormente passou a ser denominado Public-Private Partnership. O investimento, no setor privado em serviços públicos, só vem crescendo, conforme Bennett e Iossa (2006, p. 2144):

HM Treasury (2003) estima que, ao longo do período 1998-9 a 2003-4, o investimento do setor privado em serviços públicos através de PFI foi entre 10 e 13,5\% do investimento total em infra-estrutura pública, com 451 projetos PFI para construção, incluindo 34 hospitais e 119 outros sistemas de saúde, e de 239 novas escolas e reformas (BENNETT e IOSSA, 2006). ${ }^{10}$

Outro fator que fez com que os contratos de PPP aumentassem significativamente foi a premente necessidade de diminuir os gastos públicos. Bonomi e Malvessi (2008, p. 84) citam que:

Irlanda, Portugal, Hungria, Eslovênia, República Theca e França são exemplos de países que utilizaram modelos de PPP para investimentos em infra-estrutura. Na América Latina, Chile, Argentina, Peru e México lançaram mão de PPP com diferentes resultados, em virtude da histórica necessidade de contenção de despesas governamentais, a restrição orçamentária associada a acordos com o FMI e as próprias leis domésticas de responsabilidade fiscal, que restringem a capacidade de investimento dos Estados.

Tendo em vista os inúmeros tipos de contratos que vêm da celebração de uma PPP, tendo a IFRIC 12 os condensado em dois modelos, cada um deles pode tornar-se muito complexo e abordar efeitos econômicos que poderão advir deles, pois existem muitas particularidades, como, por exemplo, no caso de se 
ter a cobrança para o usuário externo, ou se é apenas a construção de um bem público e/ou manutenção, dependendo ainda do setor a ser prestado o serviço (infraestrutura, saúde, segurança pública, dentre outros). Diante do exposto, é que a regulação vem tentar diminuir esse leque de possibilidades.

Segundo Kaplan e Rulandj (1991), a existência de regulação e a obrigatoriedade da divulgação podem representar uma falha no mercado. Em um mercado desregulamentado, os investidores não têm incentivos para considerar a informação contábil importante. Se a regulação reduzir o grau de ineficiência, haverá mais riqueza disponível a ser distribuída. A teoria econômica da regulação ainda falha ao não tratar sobre a relação entre agentes reguladores e legisladores, conforme discorrem Iudícibus e Lopes (2004, p. 237):

Apesar de representar grande evolução em relação à abordagem normativa, a Teoria Econômica da Regulação não explica a forma tomada por ela (regulação) e o processo de escolha por parte dos reguladores, ignorando a relação principal-agente entre legisladores e regulador, uma vez que, normalmente, os legisladores não tratam da regulação diretamente, mas delegam essa tarefa a uma agência ou órgão regulador.

Os agentes reguladores ao editarem uma norma devem sempre se atentar ao fator econômico a fim de representar a realidade dos fatos. Carvalho et al. (2006) argumentam que as agências reguladoras não devem esquecer a essência na representação patrimonial, se a regra deturpar a norma contábil deve ser contestada, pois demonstra uma situação patrimonial inverídica. Se as agências seguirem a sadia norma contábil, esta regra será inócua.

\subsection{Breve Revisão Bibliográfica sobre PPPs}

A revisão bibliográfica sobre PPPs, tanto nacional como internacional, enfatiza os riscos inerentes ao arranjo (Pinto, 2004; Neto, 2005; Brandão e Saraiva, 2007; Grimsey e Lewis, 2000; Parker e Hartle, 2003; Shaoul, 2005; Quiggin, 2005; Bing et al., 2005; Jin e Doloi, 2008; Iossa e Martimort, 2008).

Todavia, a IFRIC 12, em seu texto legal, não trata especificamente sobre risco. Percebe-se que o assunto foi analisado, mas sem a veemência com que é encontrado na bibliografia específica do assunto.

Pinto (2004) enfatiza que eliminar riscos em um projeto de PPP é um esforço inglório, mas mitigar os riscos é dever de todos os que se lançarem em operações no seu âmbito, não sendo só de interesse do parceiro privado, bem como do parceiro público também, pois o grau de risco elevado é uma ameaça à implantação das PPPs e sua operacionalização. Aborda, ainda, alguns tipos de riscos: político, ambiental, regulatório e contratual. 
Neto (2005) enumera também diferentes tipos de risco no ambiente de PPPs a serem ponderados tanto pela iniciativa privada como pelo parceiro público: risco de construção, financeiro (sendo variação cambial, se investidor estrangeiro, e risco de crédito), de demanda, político, de performance (riscos de redução da remuneração, penalidade ou mesmo perda do contrato por força de falhas no desempenho do parceiro privado).

Brandão e Saraiva (2007) destacaram as principais vantagens da PPP: competição ex ante; economia de escala e de aprendizagem; ineficiência ex post; complementaridade de tarefas; financiamento privado e o verdadeiro custo de capital e incentivos mais eficazes e alocação ótima de riscos (para a alocação ótima de riscos, deve-se esperar que a gestão privada só permita assumir o risco com o que pode arcar).

A Contabilidade tenta mensurar com confiabilidade os diversos tipos de riscos, que logicamente encontram limitações. A teoria contábil observa somente aquelas que possuem relevância econômica, sendo que uma das diversas funções da Contabilidade é criar modelos e técnicas que atendam a essa diversidade de fatos econômicos a fim de demonstrar a situação patrimonial das entidades o mais próximo possível da realidade.

Para ilustrar, o organograma abaixo tipifica e qualifica os riscos que afetam as PPPs:

Figura 1: Riscos principais que afetam as PPPs

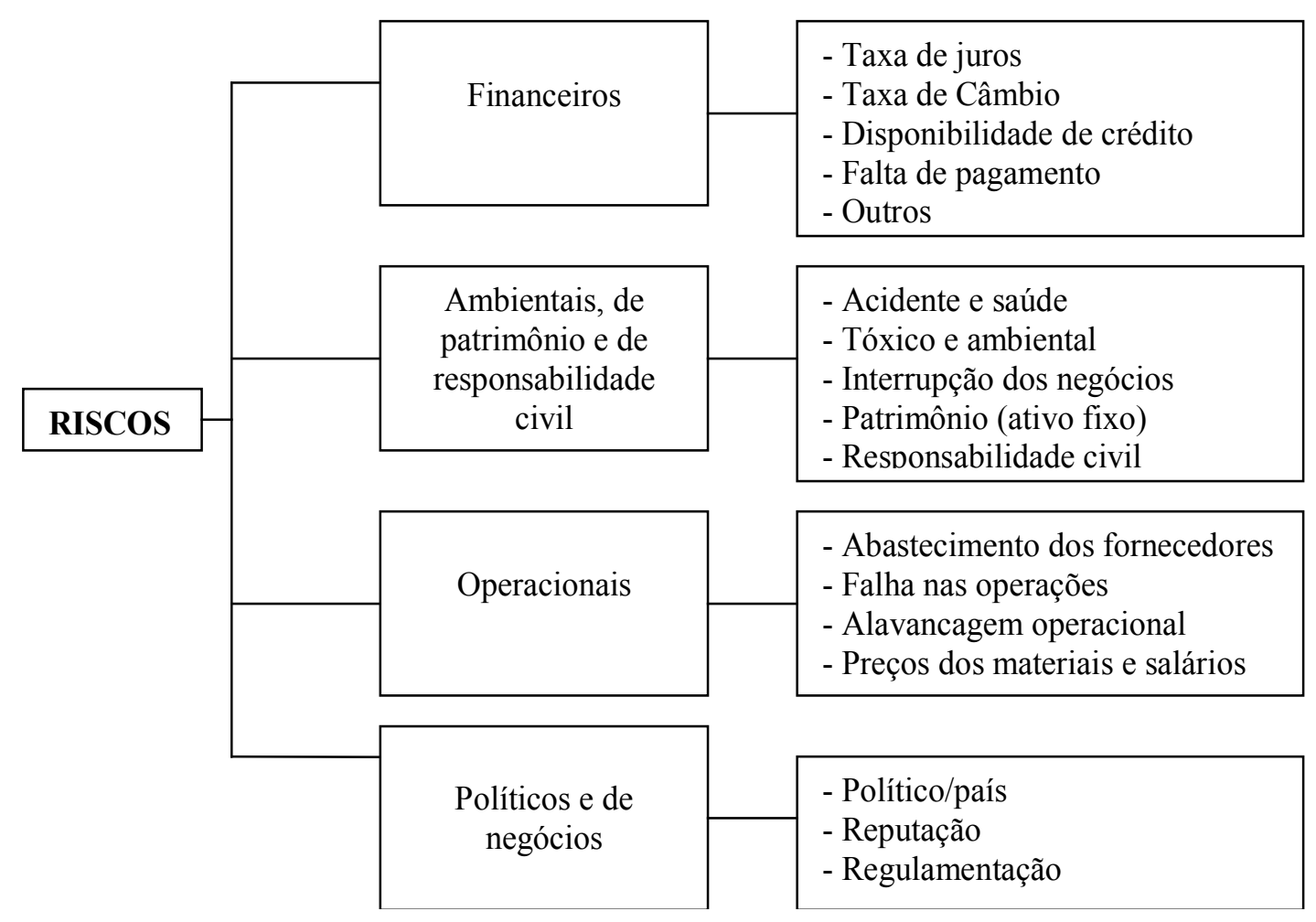

Fonte: Bonomi e Malvessi (2008, p. 25). 
A Lei n. 11.079/04, em diversos pontos, tenta minimizar esses riscos: o art. $4^{\circ}, \mathrm{VI}$, estabelece que, quando da contratação da PPP, deve prevalecer a repartição de risco entre as partes; art. $5^{\circ}$, VIII, as cláusulas dos contratos devem prever a prestação, pelo parceiro privado, de garantias de execução suficientes e compatíveis com os ônus e riscos envolvidos; art. $6^{\circ}$, parágrafo único, dispõe que o contrato poderá prever o pagamento ao parceiro privado de remuneração variável vinculada ao seu desempenho, conforme metas e padrões de qualidade; art. $8^{\circ}$, dispõe de uma série de garantias como vinculação de receitas; instituição ou utilização de fundos especiais; contratação de seguro-garantia com as companhias seguradoras que não sejam controladas pelo Poder Público; art. $9^{\circ}$, antes da celebração do contrato deverá ser constituída sociedade de propósito específico, para implantar e gerir o objeto de parceria, dentre outros dispositivos.

Percebe-se claramente que o legislador preocupou-se em dirimir os riscos, pois, conforme já mencionado, trata-se de contratos diversos com características das mais variadas. Logicamente que eliminar totalmente risco nesses arranjos, é impossível.

No âmbito internacional, destacam-se inúmeros papers que tratam sobre PPPs e seus riscos. Grimsey e Lewis (2000) analisaram os riscos de arranjos de PPP sob várias perspectivas. Parker e Hartle (2003) estudaram a economia de PPP e PFI, o estudo de caso destaca tanto no âmbito das PPP/ PFIs e seus potenciais custos de transação, com a assimetria de informação, ativo específico e a possibilidade de comportamento oportunista, no setor de defesa do Reino Unido.

Shaoul (2005) estudou a política do Governo do Reino Unido de Private Finance Initiative (PFI) e levanta uma série de questões sobre a racionalidade e implicações de utilizar financiamento privado, mais caro do que o financiamento público, para serviços públicos essenciais. Este trabalho revela decisões sobre conceitos ambíguos de transferência de riscos e value of money no nível de cada hospital, em vez do sistema ou sociedade como um todo.

Quiggin (2005) destaca que o argumento central a favor das PPPs é que elas permitem uma transferência de risco socialmente desejável do setor público para o privado. O principal objetivo do artigo é examinar a possibilidade de que a inclusão de forma adequada de PPP pode melhorar a gestão de riscos associados à falha do contrato.

Bing et al. (2005) realizaram uma survey com o objetivo de explorar a atribuição de risco em PPP/ PFI em projetos de construção no Reino Unido. Três níveis de classificação (maior, médio e baixo) de meta foram propostos relacionados com a natureza dos projetos. A maioria dos projetos remanescentes de riscos, especialmente aqueles em risco de nível médio (ou seja, diretamente associado ao projeto em si), deve ser atribuída aos parceiros do setor privado. Quatro fatores de risco: nível de suporte público, projeto de aprovação e permissão, variação de 
contrato e da falta de experiência não podem facilmente ser alocados a uma parte particular ou sem divisão.

Jin e Doloi (2008) trataram da alocação de risco em PPP por meio de um estudo empírico sob a perspectiva da Economia dos custos de transação (TCE). Iossa e Martimort (2008) apresentaram um modelo básico de aquisição de ambiente multitarefa, para redução dos custos e melhoria de qualidade. Apontam que PPP é adequada para os setores de transportes, água, infraestrutura onde a qualidade é fundamental e a demanda é relativamente estável, enquanto sugere que as PPPs são menos propensas aos asilos para idosos, escolas onde a qualidade dos serviços é essencialmente determinado pelo investimento em capital humano, ou serviços de TI, onde evolui rapidamente ao longo do tempo.

\subsection{Características Econômicas mais Relevantes das PPPs}

Na expectativa de buscar uma representação contábil aderente à realidade econômica dos contratos, a IFRIC 12 versa sobre dois tipos de contratos:

1) Quando o operador constrói ou adquire de terceiros com a finalidade de prestar serviços dispostos no contrato; e

2) Quando já existe a infraestrutura na qual o concedente permite o acesso ao operador para prestar serviços do contrato.

A partir do momento em que existe mais de uma parte em um contrato, podem surgir alguns tipos de conflitos, principalmente porque uma grande parte não conhece a ação do outro agente, e cláusulas obscuras podem também contribuir para aumentar a assimetria informacional. A teoria dos contratos vem para explicar esses eventos, possuindo duas vertentes: a teoria da Economia dos Custos de Transação (ECT) e a teoria da agência.

$\mathrm{Na}$ revisão teórica sobre a teoria dos contratos, uma importante contribuição foi a de Coase (1937) que busca a definição de firma, considerando-a como um nexo de contratos, existindo várias alternativas de escolhas e as suas consequências econômicas.

Coase também foi o primeiro a reconhecer o problema dos contratos incompletos, o que em um contrato de PPP é um ponto primordial, pois ocasiona pedidos de renegociações, pois pode vir a onerar uma das partes, ou seja, o parceiro público ou privado. Bettingnies e Ross (2004, p. 140) contextualizam este fato:

Coase (1937) foi o primeiro a reconhecer as conseqüências econômicas dos contratos incompletos, e suas idéias, bem como as de Williamson (1975, 1979, 1985), e Klein, Crawford e Alchian (1978), desencadeando uma nova literatura sobre o assunto. Argumentouse que devido ao seu caráter incompleto, os contratos têm de ser constantemente revistos e / ou renegociados com o passar do tempo 
(contratos de longo prazo são inviáveis), e o problema da ineficiência ex-post gerados por relações específicas de investimentos não podem ser facilmente mitigados.

Outro percursor da teoria Econômica dos Custos de Transação (ECT) foi Oliver Williamsom. Em sua obra The Economics Institutions of Capitalism (1985, p. 20-22), apresenta o problema da Economia dos Custos de Transação como um problema de contratação e analisa quais são os custos de um contrato ex ante e ex post. Cita que é útil diferenciar os custos ex ante e ex post, sendo que o primeiro são custos de elaboração, negociação e garantias. E ainda tem que ser muito bem elaborado, pois existem várias contingências a serem reconhecidas e acordadas pelas partes previamente, senão o contrato pode ser incompleto. Os custos de contratos ex post são de várias formas como: custos de um contrato não alinhados; custos associados à estrutura de governança entre outros. Um fato complicador é que esses custos são interdependentes, devendo ser abordados simultaneamente, em vez de sequencialmente e de difícil mensuração.

A partir da assinatura do arranjo, podem ocorrer dificuldades em seu cumprimento, devido a contratos mal elaborados e/ou interpretados. Jensen e Meckling (1976) estudaram os elementos da teoria da agência, a teoria dos direitos de propriedade e a teoria das finanças e concluem que custo de agência é tão real quanto qualquer outro custo.

Segundo Iudícibus e Lopes (2004), alguns problemas surgem na prática a respeito da execução e imposição dos contratos, destacando duas situações: informação imperfeita, que é aquela que os agentes conhecem as regras, mas desconhecem o comportamento dos outros agentes; e informação incompleta, onde as regras não estão totalmente claras e ainda, na prática, podem ocorrer atos não esperados que irão gerar custos adicionais de transação, aumentando também os riscos do evento. Nesse contexto, a Contabilidade tem importante papel, devendo fornecer informações úteis a fim de diminuir a assimetria informacional existente nesses eventos. "A contabilidade surge para resolver problemas econômicos da firma", segundo Iudícibus e Lopes (2004, p. 176)

De acordo com Lopes e Martins (2007), cinco características essenciais das transações impactam diretamente os custos de transação:

1) especificidade dos investimentos necessários para realizar a transação: quando a firma precisa fazer um investimento para produzir um produto extremamente específico que atende somente uma finalidade e cliente muitos problemas podem surgir.

2) frequência na qual as transações similares ocorrem e a duração ou período de tempo no qual elas são repetidas: se as transações realizadas entre duas firmas são similares e conduzidas com freqüência sobre um longo intervalo de tempo, é de se supor que essas empresas criarão modelos alternativos de con- 
tratação. Reduzindo os custos jurídicos da operação começam a entrar em cena conceitos como confiança e fidelidade.

3) complexidade da transação e a incerteza sobre qual performance será requerida das partes: nesses casos as partes tendem a estabelecer contratos genéricos, a realização de contratos nesta situação é bastante complexa e custosa.

4) dificuldade de mensurar a performance: uma vez que a performance não pode ser mensurada facilmente, a determinação dos incentivos também fica comprometida.

5) grau de conexão da transação com as demais realizadas pela firma: quanto mais interligadas forem as atividades, maior a chance de termos um controle central forte para impedir que falhas venham a ocorrer por problemas de coordenação.

Todas essas características podem ocorrer nos contratos de PPP: por se tratar de serviços públicos, tem-se a especificidade dos investimentos como a captação de água e esgoto, construção, recuperação e exploração de rodovias; construção de presídios, de hospitais, escolas, dentre outros. São celebrados em um ambiente de incertezas, com custos que podem ser políticos, pois são contratos de duração de 5 a 35 anos, podendo ocorrer mudanças econômicas e políticas durante a sua execução; quanto maior a assimetria de informação nos contratos de PPP, incluindo obrigações de difícil mensuração como a performance e a eficiência do parceiro, também aumentam os custos de transação.

\subsection{Teoria Contábil}

Uma rápida revisão dos princípios contábeis é necessária, para a análise apropriada dos arranjos de PPP, pois isso é a base para a correta interpretação dos fatos econômicos. A partir da celebração do contrato entre os parceiros público e privado, devem-se analisar os efeitos econômicos que poderão advir daí e observar se eles geram fatos contábeis naquele momento ou poderão gerar, que deverão ser reconhecidos nas demonstrações contábeis, ou apenas divulgados nas notas explicativas.

A Deliberação n. 539/08, que aprova o Pronunciamento Conceitual Básico do CPC, que dispõe sobre a Estrutura Conceitual para a Elaboração e Apresentação das Demonstrações Contábeis", que já está em consonância com as normas internacionais (IAS 1), define os conceitos básicos:

Ativo: é um recurso controlado pela entidade como resultado de eventos passados e do qual se espera que resultem futuros benefícios econômicos para a entidade;

Passivo: é uma obrigação presente da entidade, derivada de eventos já ocorridos, cuja liquidação se espera que resulte em saída de recursos capazes de 
gerar benefícios econômicos;

Patrimônio Líquido: é o valor residual dos ativos da entidade depois de deduzidos todos os seus passivos.

Receitas: são aumentos nos benefícios econômicos durante o período contábil sob a forma de entrada de recursos ou aumento de ativos ou diminuição de passivos, que resultam em aumentos do patrimônio líquido e que não sejam provenientes de aporte dos proprietários da entidade; e

Despesas: são decréscimos nos benefícios econômicos durante o período contábil sob a forma de saída de recursos ou redução de ativos ou incrementos em passivos, que resultam em decréscimo do patrimônio líquido e que não sejam provenientes de distribuição aos proprietários da entidade.

Após o rápido entendimento de cada conceito, deve-se partir para o momento correto de reconhecimento, provisão ou apenas divulgação do evento. Segundo Niayma e Silva (2008 p. 128), para reconhecer um ativo, é necessário que o recurso econômico possa ser classificado como ativo; isto é feito pela resposta positiva às três perguntas a seguir: o recurso econômico irá gerar um futuro beneficio econômico? o recurso econômico é controlado pela entidade? é derivado de evento passado? Além desses itens, deve-se também levar em consideração três aspectos adicionais: a materialidade, a probabilidade de ocorrência e a confiabilidade da avaliação, conforme descrito na Figura 2:

Figura 2: Reconhecimento do ativo

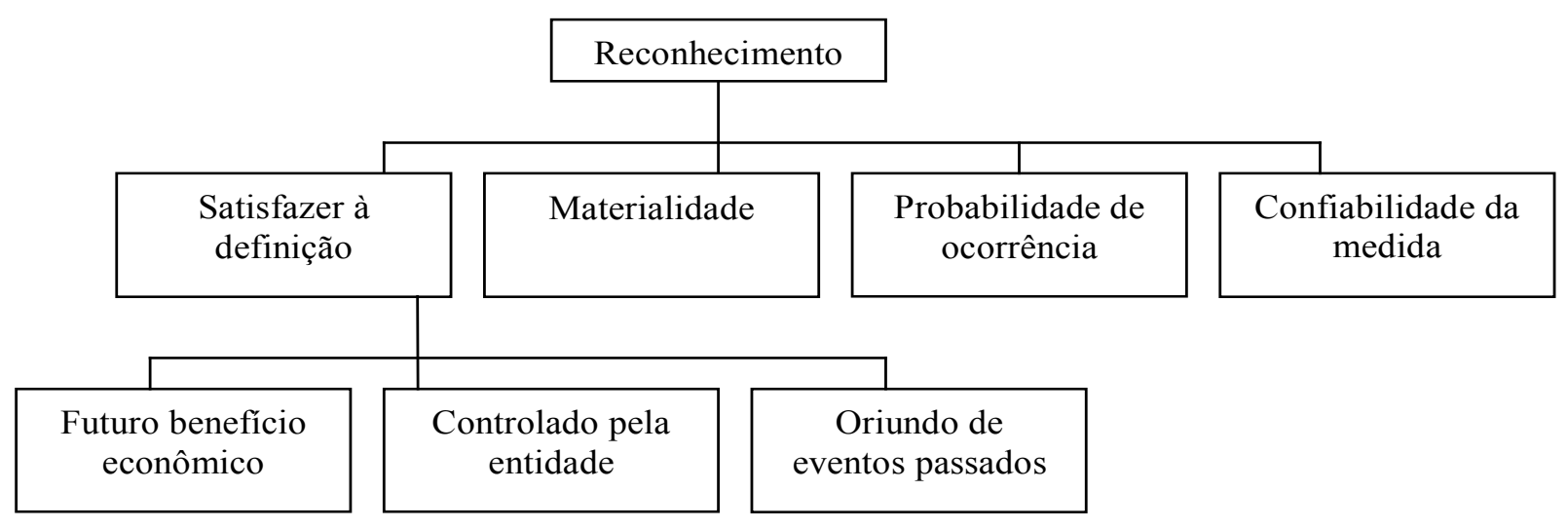

Fonte: Elaborada pelos autores.

Quanto ao momento correto de reconhecer um passivo nas demonstrações contábeis, é quando se tem uma provável saída de recursos com bases de mensuração confiáveis. Lopes e Martins (2007, p. 145) contextualizam este fato:

Sugerimos que os passivos sejam reconhecidos na sua capacidade de informar sobre os sacrifícios de recursos futuros da entidade. Esses sacrifícios devem ser reconhecidos de acordo com sua probabilidade de ocorrência e não simplesmente pela sua obrigatoriedade jurídica. 
Percebe-se, nessa citação, claramente a prevalência da essência sobre a forma. Quanto ao reconhecimento de receita, apesar de que nem todo aumento de ativo e diminuição de passivo ser uma receita, contabiliza-se uma receita quando aumenta um ativo ou diminui de passivo concomitantemente. As despesas também são reconhecidas quando há uma diminuição de um ativo ou aumento do passivo. Destaca-se o regime de competência, quando se reconhece o fato econômico no momento em que ocorre, e não quando há a entrada e saída de recursos financeiros. O comentário seguinte vem clarear esse contexto:

$\mathrm{Na}$ verdade, o regime de competência nada mais é do que a redistribuição temporal dos fluxos de caixa de formar a se melhorar a informação. (LOPES e MARTINS, 2007, p. 147)

Destaca-se o princípio da prudência a fim de que, na elaboração das demonstrações contábeis, os ativos e as receitas não venham a ser superestimados; e passivos e despesas, subestimados. A introdução do conceito de fair value em detrimento do custo histórico, para a classificação dos ativos, é que o valor justo traz um conteúdo informativo mais perto da realidade da situação patrimonial da firma, isto quando for possível uma mensuração correta. Caso contrário, adotase o custo histórico realizando o teste de impairment periodicamente, nunca se esquecendo da confiabilidade da informação.

Portanto um dos principais fatos contábeis é o registro dos ativos decorrentes das PPPs por parte do parceiro privado. Já que os ativos cedidos ou construídos não são do controle do parceiro privado (ou seja, não são adequados à definição de ativos), resta saber quais são os ativos contábeis dessas entidades.

\section{Contabilização das PPPs pela IFRIC 12}

Para contabilizar as receitas dos contratos de concessão, é necessário se definir com bastante precisão qual a sua natureza, o melhor método de mensuração.

A natureza, a magnitude e o momento de ocorrência das receitas constituem problemas fascinantes na teoria da contabilidade. Na prática, definições de receita são comumente associadas a procedimentos contábeis específicos, certos tipos de variação de valor e regras presumidas ou implícitas de determinação do momento no qual uma receita deve ser registrada. (HENDRIKSEN, 2007, p. 224)

As receitas, bem como as despesas, são de grande importância, pois afetam diretamente a demonstração de resultados do exercício, sendo de caráter eminentemente econômico. 
Vários eventos, como mensuração dos riscos, performance e eficiência das PPPs precisam ser estimados e, para tanto, são necessárias bases confiáveis, do contrário não devem ser reconhecidos, devem ser divulgados em notas explicativas, em atendimento aos pressupostos básicos e as características qualitativas das demonstrações contábeis.

[...] Em muitos casos, o custo ou valor precisa ser estimado; o uso de estimativas razoáveis é uma parte essencial da preparação das demonstrações contábeis e não prejudica a sua confiabilidade. Quando, entretanto, não puder ser feita uma estimativa razoável, o item não deve ser reconhecido no balanço patrimonial ou na demonstração do resultado (CPC 01, item 86).

Pela IFRIC 12, existem dois tipos de ativos dos parceiros privados. Um primeiro, denominado ativo financeiro, é reconhecido somente quando o arranjo dispõe sobre direitos incondicionais de receber pela construção e/ou pela operação serviço, tanto por dinheiro ou outro ativo financeiro. Nesses casos, o concedente tem pouca discrição para evitar o pagamento, mesmo quando o pagamento é contingente à qualidade e eficiência. Ou seja, se existem direitos legais de receber recursos que irão gerar benefícios econômicos futuros e com uma base de mensuração confiável, tais fatos implicam o reconhecimento a valor justo dos instrumentos financeiros.

Segundo a $I A S 32^{11}$, um ativo financeiro é qualquer ativo em dinheiro, um instrumento patrimonial de uma outra entidade ou um direito contratual. Nesse caso, o ativo será classificado como instrumento financeiro, pois instrumento financeiro é qualquer contrato que resulta em um ativo financeiro de uma entidade e um passivo financeiro ou instrumento patrimonial de outra entidade, sendo o valor devido contabilizado como: um empréstimo ou recebível; um ativo financeiro disponível para venda; ou, se assim for designado no momento do reconhecimento inicial, um ativo financeiro pelo valor justo.

Após o reconhecimento dos instrumentos financeiros, a entidade deverá classificá-los em quatro categorias distintas, conforme suas características. São elas: mantidos para negociação (held-for-trading), mantidos até o vencimento (held-to-maturity), empréstimos e recebíveis (loans and receivables) e disponíveis para venda (available-for-sale) (CARVALHO, LEMOS e COSTA, 2006).

A IFRIC 12 interpreta que o contrato de PPP não pode ser classificado como held-to-maturity (mantidos até o vencimento), tendo em vista sua característica $^{12}$, pois são ativos financeiros com pagamentos fixos ou determináveis, e a entidade tem a intenção, a capacidade de mantê-lo até o vencimento. Como se pode perceber, os contratos de PPPs não têm claramente esta peculiaridade.

E também não deve ser classificado como derivativo ${ }^{13}$, pois não possui os requisitos exigidos pela $I A S 39$, porque o valor de um derivativo pode mudar 
em resposta à mudança específica na taxa de juros, preço de títulos e valores mobiliários, preço de commodities, taxa de câmbio, índice ou taxa de preços, rating ou índice de crédito, ou outra variável similar; nenhum ou pouco investimento líquido inicial é requerido em relação a outros tipos de contratos que tenham resposta similar às mudanças nas condições do mercado; e a liquidação se dará em data futura.

Portanto, no caso de o contrato estabelecer fluxos de caixa futuros com baixíssima possibilidade de variação dos fluxos, contabiliza-se um Contas a Receber conforme o direito de receber vai sendo ganho economicamente pelo parceiro.

Pode, por outro lado, haver também um arranjo em que o operador deve reconhecer um ativo intangível, na medida em que recebe um direito (licença) para cobrar dos usuários do serviço público, por exemplo, cobrança de pedágio por utilizar a rodovia, não é um direito incondicional de receber um ativo financeiro, pois os montantes estão subordinados à medida que o público utiliza o serviço. Deve-se então reconhecer um ativo intangível pelo valor justo. Ou seja, no caso dos fluxos futuros serem incertos, o que o parceiro privado está ganhando economicamente é o direito de poder cobrar tarifas dos usuários dos serviços. Esse direito é o verdadeiro ativo; logo um intangível.

Nesses casos, aplica-se a $I A S 38$, parágrafos $45-47^{14}$. No Brasil, a CVM, em abril de 2008, colocou em audiência pública a minuta de deliberação sobre os ativos intangíveis em conjunto com o CPC, mas, até o momento, ainda não foi aprovada. A minuta define ativo intangível como um ativo monetário identificável sem substância física ou o ágio pago por expectativa de rentabilidade futura (Goodwill). Intangível, segundo a $I A S 38$, é um ativo não monetário identificável sem substância física, o que não se pode confundir com o Goodwill (ágio pago por expectativa de rentabilidade futura). Um ativo intangível pode ser gerado por direitos contratuais ou outros direitos legais, independente de tais direitos serem transferíveis ou separáveis da entidade ou de outros direitos e obrigações. $O$ custo de um ativo intangível é avaliado pelo valor justo, a não ser que não tenha natureza comercial (quando tem expectativa de rentabilidade futura, ou seja, obter benefícios econômicos futuros) ou o seu valor justo não puder ser mensurado corretamente.

Por ilustrar melhor, um contrato de PPP de reforma de duplicação de uma rodovia e remuneração será uma contrapartida pecuniária do governo; e a outra, o parceiro privado recebe uma licença para explorar com cobrança de tarifa durante 20 anos. Esse arranjo irá envolver o reconhecimento tanto de um ativo financeiro e um ativo intangível, sendo que, nesse caso, devem ser contabilizados em contas separadas.

A IFRIC 12 dispõe ainda que o operador deve reconhecer e mensurar as receitas e custos de acordo com a $I A S 11^{15}$ (contratos de construção) quando 
relacionados com a construção ou melhoria da infraestrutura e $I A S 18^{16}$ (receitas) quando da prestação de serviços (esses aspectos não são abordados mais profundamente neste artigo).

Dos contratos surgem obrigações que o operador tem que cumprir: manter a infraestrutura em um determinado nível de manutenção; e restaurar a infraestrutura em uma determinada condição, antes de ser entregue ao concedente, no final do contrato de serviço.

Essas obrigações contratuais para manter ou restaurar infraestrutura, com exceção de qualquer elemento upgrade (IAS 11), devem ser contabilizadas em conformidade com a IAS 37 - Provisões, Passivos Contingentes e Ativos Contingentes, ou seja, na melhor estimativa da despesa que seria necessária para resolver a obrigação presente na data do balanço. Nenhuma infraestrutura, construída ou não, pode ser reconhecida como ativo permanente da concessionária (parágrafo 11, IFRIC 12).

Para finalizar este tópico, faz-se um breve relato do que foi tratado até o momento. A IFRIC 12 padroniza os contratos de PPP em dois: quando o operador constrói ou adquire de terceiros com a finalidade de prestar serviços dispostos no contrato; e quando já existe a infraestrutura na qual o concedente permite o acesso ao operador para prestar serviços do contrato. Esses contratos possuem efeitos econômicos que se não mensurados e reconhecidos pela Contabilidade podem gerar uma representação patrimonial da firma não verdadeira. Vale ressaltar que a classificação pela IFRIC não é excludente. Pode haver contratos de PPP que tenham as duas características concomitantemente: ativos financeiros (contas a receber com baixo nível de risco) e ativos intangíveis (direito a prováveis fluxos futuros, com níveis de risco mais elevados). Para exemplificar, a partir da adjudicação de um contrato de PPP em que a empresa adquire o direito de construir um presídio, onde o parceiro público tem pouca discricionariedade para evitar o pagamento, a concessionária deve reconhecer um instrumento financeiro de acordo com as cláusulas do arranjo, pois passou a ter um direito contratual. Deve-se também estimar os custos dessa construção para estar provisionando, ou somente divulgando o fato contábil. Um dos pontos que já foi dito de bastante incerteza é a alocação dos riscos, pois se trata de um contrato de longo prazo, com o setor público, gerando os diversos tipos de riscos, financeiro, político, operacional, regulação, operacional dentre os diversos que já foram os citados neste estudo. Por isso, é de suma importância a elaboração de um contrato bem feito.

\subsection{Exemplo de contabilização de um contrato de PPP}

Não sendo possível ainda uma análise empírica, demonstram-se abaixo duas situações hipotéticas para ilustrar a contabilização de um contrato de PPP, 
tendo por base os exemplos contidos na própria IFRIC 12.

\section{Exemplo 1 - Ativos Financeiros}

Foi celebrado um contrato para construir uma rodovia, em dois anos, e, após a construção, o parceiro deverá manter e operar a rodovia durante oito anos e ainda recuperar a rodovia ao final do ano oito. O contrato termina em dez anos. Foram estimados os seguintes custos: de construção ( $\$ 500$ por ano); de manutenção ( $\$$ 10 por ano) e para recuperar a rodovia $(\$ 100)$. O contrato termina em dez anos. O termo do contrato requer que o grantor irá pagar o operador $\$ 200$ por ano a partir do ano três, para deixar a rodovia à disposição do público. Para ilustração desse exemplo, assumem-se todos os fluxos de caixa ao final de cada ano.

\begin{tabular}{|c|c|c|}
\hline \multicolumn{3}{|c|}{ DADOS CONTRATUAIS } \\
\hline \multicolumn{3}{|c|}{ Contrato requer construção de estrada } \\
\hline \multicolumn{3}{|c|}{ Duração da construção: 2 anos } \\
\hline \multicolumn{3}{|c|}{ Manter e operar a estrada por oito anos } \\
\hline \multicolumn{3}{|c|}{ Recapear a estrada ao final do oitavo ano (remunerada) } \\
\hline \multicolumn{3}{|c|}{ Custos Estimados } \\
\hline Serviços & Ano & Valor \\
\hline Construção & 1 & 500 \\
\hline Construção & 2 & 500 \\
\hline Operação & 3 ao 10 & 10 \\
\hline Recapeamento & 8 & 100 \\
\hline
\end{tabular}

\begin{tabular}{|l|c|c|}
\hline \multicolumn{3}{|c|}{ Remuneração Pactuada } \\
\hline \multicolumn{1}{|c|}{ Serviços } & Ano & Valor \\
\hline Construção & 1 & Custos $+5 \%$ \\
Construção & 2 & Custos $+5 \%$ \\
Operação & 3 ao 10 & 200 \\
Recapeamento & 8 & Custos $+10 \%$ \\
\hline
\end{tabular}

\begin{tabular}{|ll|}
\hline Taxa de juros annual (recebíveis) & $6,18 \%$ \\
Juros empréstimos & $6,70 \%$ \\
\hline
\end{tabular}

\begin{tabular}{|c|c|c|c|c|c|c|c|c|c|c|c|}
\hline DRE & Ano 1 & Ano 2 & Ano 3 & Ano 4 & Ano 5 & Ano 6 & Ano 7 & Ano 8 & Ano 9 & \begin{tabular}{|l|} 
Ano 10 \\
\end{tabular} & TOTAL \\
\hline Receitas & 525 & 525 & 12 & 12 & 12 & 12 & 12 & 122 & 12 & 12 & .256 \\
\hline Despesas & $(500)$ & $(500)$ & (10) & (10) & (10) & (10) & (10) & $(110)$ & (10) & (10) & .180 \\
\hline Receitas fin & & 32 & 67 & 59 & 51 & 43 & 34 & 25 & 21 & 11 & \\
\hline Despesas fi & & (34) & (69) & (61) & (53) & (43) & (33) & (23) & (19) & (7) & (342) \\
\hline Resultado Líquido & 25 & 24 & () & & 1 & 2 & 3 & 14 & 5 & 6 & \\
\hline
\end{tabular}

\begin{tabular}{|l|c|c|c|c|c|c|c|c|c|c|}
\hline Posição Financeira & Ano 1 & Ano 2 & Ano 3 & Ano 4 & Ano 5 & Ano 6 & Ano 7 & Ano 8 & Ano 9 & Ano 10 \\
\hline Recebível 1 & $\mathbf{5 2 5}$ & 1.050 & 894 & 773 & 645 & 508 & 363 & 319 & 156 & $(11)$ \\
Juros & & 32 & 67 & 59 & 51 & 43 & 34 & 25 & 21 & 11 \\
$\quad$ Recebível Total & $\mathbf{5 2 5}$ & $\mathbf{1 . 0 8 2}$ & $\mathbf{9 6 1}$ & $\mathbf{8 3 3}$ & $\mathbf{6 9 6}$ & $\mathbf{5 5 1}$ & $\mathbf{3 9 7}$ & $\mathbf{3 4 4}$ & $\mathbf{1 7 7}$ & \\
Caixa (Empréstimo) & $(500)$ & $(1.034)$ & $(913)$ & $(784)$ & $(646)$ & $(500)$ & $(343)$ & $(276)$ & $(105)$ & 78 \\
Capital Próprio & $\mathbf{2 5}$ & 49 & 49 & 49 & 50 & 52 & 54 & 68 & $\mathbf{7 2}$ & 78 \\
TOTAL PASSIVO & $\mathbf{5 2 5}$ & $\mathbf{1 . 0 8 2}$ & $\mathbf{9 6 1}$ & $\mathbf{8 3 3}$ & $\mathbf{6 9 6}$ & $\mathbf{5 5 1}$ & $\mathbf{3 9 7}$ & $\mathbf{3 4 4}$ & $\mathbf{1 7 7}$ & \\
\hline
\end{tabular}

\begin{tabular}{|c|c|c|c|c|c|c|c|c|c|c|c|}
\hline DFC & Ano 1 & Ano 2 & Ano 3 & Ano 4 & Ano 5 & Ano 6 & Ano 7 & Ano 8 & Ano 9 & Ano 10 & гот \\
\hline ece & & & 200 & 200 & 200 & 200 & 200 & 200 & 200 & 200 & \\
\hline & (500) & (500) & $(10$ & (10) & $(10$ & 10) & (10) & (110) & (1) & (10) & 1.1 \\
\hline & & & & & & & & (23) & & (7) & (342) \\
\hline aixa líquido & $(500)$ & (534) & 121 & 129 & 137 & 147 & 157 & 67 & 171 & 183 & 78 \\
\hline
\end{tabular}

Contabilização: como já vimos no decorrer deste artigo, o operador deve reconhecer o contrato quanto a receitas e despesas, de acordo com a $I A S$ 11 (contratos de construção) e $I A S 18$ (receitas). Os custos de cada atividade de construção, de operação e de recuperação são reconhecidos como gastos com 
referência à fase de conclusão de cada atividade. As receitas devem ser reconhecidas pelo fair value. $\mathrm{O}$ montante devido pelo concedente encontra definição de recebíveis na IAS 39 - Instrumentos Financeiros: Reconhecimento e mensuração. Recebíveis são mensurados inicialmente pelo fair value, e depois o custo deverá ser amortizado. Para exemplificar, assume-se que o operador financia o contrato inteiramente, a dívida e os juros. Ele paga juros de $6,7 \%$ por ano do restante da dívida. A taxa de juros efetiva é de $6,18 \%$.

\section{Exemplos 2 - Ativos Intangíveis}

Assumem-se os mesmos dados do exemplo anterior, com a alteração que o operador terá o direito de cobrar pedágio dos usuários da rodovia, prevendo que o número de veículos será constante durante o contrato e irá receber $\$ 200$ por ano a partir do ano três. Deve-se então reconhecer um ativo intangível, ou seja, um direito a receber dos usuários a partir do terceiro ano.

Contabilização: o operador fornece os serviços de construção para o cedente em troca de um ativo intangível, isto é, um direito de cobrar dos usuários a partir do terceiro ano. De acordo com a IAS 38 - Ativos Intangíveis, o operador reconhece o intangível a fair value. Durante a fase de construção, o custo da construção capitaliza os custos do empréstimo como é permitido na $I A S 23$ - Custos do empréstimo.

De acordo com a $I A S 38$, o ativo intangível é amortizado durante o período em que se espera que estejam disponíveis para uso por parte do operador, ou seja, 3-10 anos. O montante amortizável do ativo intangível (\$1.084) é atribuído através de um método linear. A amortização anual é, portanto, cobrar $\$ 1.084 / 8$ anos $=\$$ 135 por ano. O operador reconhece as receitas e despesas, de acordo com a $I A S$ 11 (contratos de construção). E a receita pelo fair value recebida ou a receber e o rendimento sobre os custos de construção, ou seja, \$525. A obrigação pelo desgaste da rodovia durante a fase de funcionamento é reconhecida e mensurada de acordo com a IAS 37 Provisões, Passivos Contingentes e Ativos Contingentes, isto é, na melhor estimativa da despesa que seria necessária para resolver a obrigação presente na data do balanço.

Para efeitos desta ilustração, presume-se que os termos da obrigação contratual são de tal ordem que a melhor estimativa da despesa necessária para liquidar a obrigação, em qualquer data, é proporcional ao número de veículos que têm usado a estrada até essa data e aumenta a \$ 17 (a serem descontados a valor presente) por ano. Para exemplificar, assume-se que o operador financia o contrato inteiramente, a dívida e os juros. Ele paga juros de $6,7 \%$ por ano do restante da dívida. Se o fluxo de caixa e o valor justo continuam a ser os mesmos previstos, o fluxo de caixa, demonstração de resultado e balanço do operador ao longo da 
duração do contrato será de:

\begin{tabular}{|l|}
\hline \multicolumn{2}{|c|}{ DADOS CONTRATUAIS } \\
\hline Contrato requer construção de estrada \\
\hline Duração da construção: 2 anos \\
\hline Manter e operar a estrada por oito anos \\
\hline Recapear a estrada ao final do oitavo ano (obrigação) \\
\hline \\
\hline \begin{tabular}{ll}
\hline Taxa de juros mercado $\quad 6,00 \%$ \\
Juros empréstimos & $6,70 \%$ \\
\hline
\end{tabular}
\end{tabular}

\begin{tabular}{|l|c|c|}
\hline \multicolumn{3}{|c|}{ Custos Estimados } \\
\hline \multicolumn{1}{|c|}{ Serviços } & Ano & Valor \\
\hline Construção & 1 & 500 \\
Construção & 2 & 500 \\
Operação & 3 ao 10 & 10 \\
Recapeamento & 8 & 100 \\
\hline
\end{tabular}

\begin{tabular}{|l|c|c|}
\hline \multicolumn{3}{|c|}{ Remuneração Pactuada } \\
\hline \multicolumn{1}{|c|}{ Serviços } & Ano & Valor \\
\hline Construção & 1 & Custos $+5 \%$ \\
Construção & 2 & Custos $+5 \%$ \\
Operaçãa: pedágio & 3 ao 10 & 200 \\
\hline
\end{tabular}

\begin{tabular}{|c|c|c|c|c|c|c|c|c|c|c|}
\hline DRE & Ano 1 & Ano 2 & Ano 3 & Ano 4 & Ano 5 & Ano 6 & Ano 7 & Ano 8 & Ano 9 & Ano 10 \\
\hline Receitas (construção) & 525 & 525 & 200 & 200 & 200 & 200 & 200 & 200 & 200 & 200 \\
\hline Amortização intangível & & & (135) & (135) & (135) & (135) & (135) & (135) & (135) & (135) \\
\hline Despesas com obri & & & $(12)$ & $(14)$ & $(16)$ & (18) & $(20)$ & (22) & 0 & 0 \\
\hline Despesas ( & $(500)$ & (500) & & & & & & & & \\
\hline Despesas 0 & & & $(10$ & $(1$ & $(1 \mathrm{c})$ & & $(1$ & $(1$ & & (10) \\
\hline Despesas financeiras & & & (69) & (61) & (53) & (43) & (33) & (23) & (19) & (7) \\
\hline Resultado Líquido & 25 & 25 & (26) & (21) & (14) & (6) & 1 & 10 & 36 & 48 \\
\hline
\end{tabular}

\begin{tabular}{|l|c|c|c|c|c|c|c|c|c|c|}
\hline Posição Financeira & Ano 1 & Ano 2 & Ano 3 & Ano 4 & Ano 5 & Ano 6 & Ano 7 & Ano 8 & Ano 9 & Ano 10 \\
\hline Intangível & 525 & 1.084 & 948 & 813 & 677 & 542 & 406 & $\mathbf{2 7 1}$ & 135 & 0 \\
\hline Ativo Total & $\mathbf{5 2 5}$ & $\mathbf{1 . 0 8 4}$ & $\mathbf{9 4 8}$ & $\mathbf{8 1 3}$ & $\mathbf{6 7 7}$ & $\mathbf{5 4 2}$ & $\mathbf{4 0 6}$ & $\mathbf{2 7 1}$ & $\mathbf{1 3 5}$ & $\mathbf{0}$ \\
Caixa (Empréstimo) & 500 & 1.034 & 913 & 784 & 646 & $\mathbf{5 0 0}$ & 343 & 276 & 105 & $(78)$ \\
\hline Obrigação (recapeamento) & 0 & 0 & 12 & 26 & 42 & 59 & 79 & 0 & 0 & 0 \\
\hline Capital Próprio & 25 & 50 & 24 & 3 & $(11)$ & $(17)$ & $(16)$ & $(6)$ & 30 & 78 \\
TOTAL PASSIVO & $\mathbf{5 2 5}$ & $\mathbf{1 . 0 8 4}$ & $\mathbf{9 4 8}$ & $\mathbf{8 1 3}$ & $\mathbf{6 7 7}$ & $\mathbf{5 4 2}$ & $\mathbf{4 0 6}$ & $\mathbf{2 7 1}$ & $\mathbf{1 3 5}$ & $\mathbf{0}$ \\
\hline
\end{tabular}

\begin{tabular}{|l|c|c|c|c|c|c|c|c|c|c|c|}
\hline DFC & Ano 1 & Ano 2 & Ano 3 & Ano 4 & Ano 5 & Ano 6 & Ano 7 & Ano 8 & Ano 9 & Ano 10 & TOTAL \\
\hline Recebimentos & 0 & 0 & 200 & 200 & 200 & 200 & 200 & 200 & 200 & 200 & $\mathbf{1 . 6 0 0}$ \\
Custos contratuais & $(500)$ & $(500)$ & $(10)$ & $(10)$ & $(10)$ & $(10)$ & $(10)$ & $(110)$ & $(10)$ & $(10)$ & $(1.180)$ \\
Juros de empréstimos & 0 & $(34)$ & $(69)$ & $(61)$ & $(53)$ & $(43)$ & $(33)$ & $(23)$ & $(19)$ & $(7)$ & $(342)$ \\
Caixa líquido & $(\mathbf{5 0 0})$ & $(\mathbf{5 3 4})$ & $\mathbf{1 2 1}$ & $\mathbf{1 2 9}$ & $\mathbf{1 3 7}$ & $\mathbf{1 4 7}$ & $\mathbf{1 5 7}$ & $\mathbf{6 7}$ & $\mathbf{1 7 1}$ & $\mathbf{1 8 3}$ & $\mathbf{7 8}$ \\
\hline
\end{tabular}

\begin{tabular}{|l|c|c|c|c|c|c|c|c|c|c|}
\multicolumn{1}{c}{1} & 2 & 3 & 4 & 5 & 6 & 7 & 8 & 9 & 10 \\
\hline Obrigação & Ano 1 & Ano 2 & Ano 3 & Ano 4 & Ano 5 & Ano 6 & Ano 7 & Ano 8 & Ano 9 & Ano 10 \\
\hline Nominal & 0 & 0 & 17 & 34 & 51 & 68 & 85 & 102 & & \\
\hline VP & & & 12 & 26 & 42 & 59 & 79 & 100 & & \\
$\quad$ Efeito na DRE & & & $\mathbf{1 2}$ & $\mathbf{1 4}$ & $\mathbf{1 6}$ & $\mathbf{1 8}$ & $\mathbf{2 0}$ & $\mathbf{2 2}$ & & \\
\hline
\end{tabular}

Para concluir a análise dos exemplos, percebe-se facilmente que os fluxos de caixa dos dois exemplos não se alteram, ou seja, o contrato gerando um ativo financeiro ou um intangível, não há mudança no caixa. Quanto ao resultado líquido, já temos variações significativas, no desvio padrão:

\begin{tabular}{|l|c|}
\hline Contrato Exemplo 01 & \\
\hline Média & 9 \\
\hline Desvio padrão & 10 \\
\hline
\end{tabular}

\begin{tabular}{|l|l|}
\hline Contrato Exemplo 02 & \\
\hline Média & 8 \\
\hline Desvio padrão & 25 \\
\hline
\end{tabular}

Pode-se inferir dessa simples comparação que, nos contratos que geram um ativo intangível, o risco é bem maior do que um que gera um ativo financeiro, o que em estudos futuros poderá ser testado empiricamente para atestar a veracidade ou não deste fato.

\section{Considerações Finais}


A principal limitação deste artigo é a recente normatização quanto à contabilização dos contratos de PPPs, impossibilitando uma análise empírica dos demonstrativos contábeis das empresas operadoras desses contratos, tanto em nível nacional como internacional, o que será possível a partir dos balanços anuais referentes ao ano de 2008. Por isso, optou-se por uma análise normativa da IFRIC 12, proporcionando uma visão geral ela, visando o modo como deverão ser contabilizados os arranjos, e também uma breve revisão literária sobre os diversos riscos que envolvem os contratos.

Nota-se que a mensuração dos riscos é matéria polêmica de difícil mensuração tanto econômica quanto contábil, em que a norma foi omissa, sendo um dos seus pontos negativos. Pela análise dos dois exemplos, para diminuir os riscos, o contrato que gera somente um ativo intangível, pode-se buscar um acordo que reconheça uma parte como ativo financeiro. Como positivo, cita-se que ao tentar padronizar em dois modelos de contratos a norma vem como objeto facilitador e clareador para aplicação da essência econômica dos contratos. Devido à necessidade mundial de maiores investimentos nos setores de transporte, saúde, educação, prisional, as parcerias público-privadas tendem a aumentar e inúmeros estudos precisarão ser realizados no sentido de minimizar os riscos, bem como manter o equilíbrio econômico-financeiro, tanto do lado do governo quanto do parceiro privado, fomentando a economia como um todo.

Enfim, as normas contábeis não podem esquecer o caráter preditivo da Contabilidade, em que a essência tem que prevalecer sobre a forma, a fim de apurar com confiabilidade os fatos contábeis, apurando o resultado econômico mais próximo da realidade, proporcionando uma informação de qualidade aos diversos usuários da Contabilidade.

Como sugestão de pesquisas futuras, entende-se que haja, a princípio, duas frentes de pesquisas empríricas: 1) Após o início da divulgação das demonstrações contábeis de empresas que participam de PPPs (e concessões), haverá informações disponíveis para se verificar a relevância dessas informações contábeis no mercado de capitais, corroborando ou não o desejável efeito de transparência buscado pela IFRIC 12; 2) Com o início dos contratos de PPP no Brasil, abre-se espaço para pesquisas contábeis sobre os impactos dos contratos nas demonstrações contábeis dos parceiros privados específicos, principalmente quando se busca identificar nessas demonstrações informações sobre risco. Mesmo não mencionado neste artigo, cabe lembrar que, no Brasil, a partir do momento em que as Normas Internacionais de Contabilidade Públicas (IPSAS) começarem a fazer parte da prática de contabilidade governamental, poderão ser pesquisados, individual ou agregadamente, nas demonstrações contábeis dos concedentes, os efeitos dos contratos, sendo os principais os impactos nos níveis de endividamento e no custo social dos contratos. 


\section{Referências}

BENNETT J.; IOSSA E. Building and Managing Facilities for Public Services. Journal of Public Economics, 90, 2143-60, 2006.

BETTIGNIES, J. E. de. ROSS, T. W. The Economics of Public-Private. Canadian Public Policy / Analyse de Politiques, Vol. 30, No. 2 (Jun., 2004), p. 135-154.

BING Li; AKINTOYE A.; EDWARDS P. J; HARDCALSTLE, C. The allocation of risk in PPP/PFI construction projects in the UK. International Journal of Project Management 23 (2005) p. 25-35.

BRANDÃO Luiz E. T. SARAIVA, Eduardo C. G. Risco privado em infra-estrutura pública: uma análise quantitativa de risco como ferramenta de modelagem de contratos. RAP - Revista de Administração Pública. Rio de Janeiro 41(6): 1035-67, Nov./Dez. 2007.

BRADBURY, Michael (2007). An Anatomy of an IFRIC Interpretation. Accounting in Europe, 4 (2), 109-122. Retrieved July 24, 2008, de <http:/www. informaworld.com/10.1080/17449480701727890>.

BRASIL. Lei n. 11.079, 30 de dez. 2004. Institui normas gerais para licitação e contratação de parceria público-privada no âmbito da administração pública. Brasília.

CARVALHO, L. Nelson; LEMES, Sirlei; COSTA, Fábio Moraes da. Contabilidade Internacional: aplicação das IFRS 2005. São Paulo: Atlas, 2006.

COASE, R.H., 1937. The Nature of the Firm, Economica, November, IV, 386405.

COMISSÃO DE VALORES MOBILIÁRIOS (CVM). Deliberação n. 539/08.

ENGEL, E.; FISHER, R.; GALETOIC, A. (2007), The Basic Public Finance of Public-Private Partnerships. Mimeo, Department of Economics, Yale University.

HENDRIKSEN, Elson S. BREDA, Michael F. V. Teoria da Contabilidade. Tradução de Antonio Zoratto Sanvicente. São Paulo: Atlas, 2007.

IOSSA E.; MARTIMORT D. The Simple Micro-Economics of Public-Private Partnerships. 2008a. http://evan.lunarmania.com/ idei002/doc/by/martimort/ 
micro_economics.pdf. Acessado em 13 de julho de 2008.

IRFS - International Financial Reporting Standards (IFRSs®) and Interpretations as at 1 Jan. 2007, U. K.

IFRIC 12- Service Concession Arrangements.

IUDÍCIBUS, S.; LOPES, A. B. Teoria avançada da contabilidade. São Paulo: Atlas, 2004.

JENSEN, Michael C; MECKLING, William H. Theory of the firm: managerail behavior, agency costs and owership structure. Journal of Financial Economics, p. 305-360, Oct. 1976.

JIN, Xiao-Hua; DOLOI, Hemanta. Interpreting risk allocation mechanism in public-private partnership projects: an empirical study in a transaction cost economics perspective. Construction Management and Economics (July 2008) $26,707-721$

KAPLAN, Steven E.; RULANDJ, Robert G. Positive Theory, Rationality an Accounting Regulation. Critical Perspectives On Accounting (1991) 2, 361-374.

LOPES, A. B.; MARTINS, E. Teoria da Contabilidade: uma nova abordagem. São Paulo: Atlas, 2007.

MARTINS, Eliseu; MARTINS, Vinicius A.; MARTINS, Eric A. Normatização Contábil: ensaio sobre a sua evolução e o papel do CPC. Revista de Informação Contábil - RIC. Universidade Federal de Pernambuco, Vol. 1, nº 1, p.7-30, set./2007.

NETO, A. M. B. A eficácia das garantias oferecidas ao parceiro privado frente aos riscos oriundos do contrato de PPP. < http://jus2/uol/.com.br/doutrina/texto. asp?id=7755 $>$. Acessado em 28 de julho de 2008.

NIYAMA, Jorge Katsmui, SILVA, César Augusto Tibúrcio. Teoria da Contabilidade. São Paulo: Atlas, 2008.

PARKER, David, HARTLE, Keith. Transaction costs, relational contracting and public private partnerships: a case study of UK defence. Journal of Purchasing \& Supply Management, Vol. 9, 3, p.97-108, maio/2003.

PINTO, J. E. N. A percepção de risco nas Parcerias Público-Privadas e a Lei 11.079/2004 e seus mitigantes. <http://jus2.uol.com.br/doutrina/texto. asp?id=6156>. Acessado em 29 de Julho de 2008. 
QUIGGIN, John. Policy Forum: Financing Public Infrastructure Public-Private Partnerships: Options for Improved Risk Allocation. The Australian Economic Review, vol. 38, no. 4, p. 445-50. 2005.

SHAOUL, Jean. A critical financial analysis of the Private Finance Initiative: selecting a financing methodbor allocating economic wealth? Critical Perspectives on Accounting 16 (2005) 441-471

\title{
SIC 29 - Service Concession Arrangements: Disclosures.
}

\author{
WILLIAMSON, Oliver. The Economics Institutions of Capitalism, New York, \\ Free Press, 1985.
}

Sites:

http://www.iasB.org. Acesso em: $1^{\circ}$ de junho de 2008.

http://www.aasb.com.au/. Acesso em: $1^{\circ}$ de junho de 2008. http://www.cpc.org.br. Acesso

\begin{abstract}
Notas
[1] “As normas expedidas pela Comissão de Valores Mobiliários a que se refere o § 3o deste artigo deverão ser elaboradas em consonância com os padrões internacionais de contabilidade adotados nos principais mercados de valores mobiliários". [2]IFRIC 12- Interpretation -Service Concession Arrangements, elaborado e editado pelo IASB em novembro de 2006. [3] O International Financial Reporting Interpretations Committee (IFRIC) é o corpo interpretative da Fundação IASC, a mantenedora do IASB.

[ $\left.{ }^{4}\right]$ Original: "Accounting interpretations are likely to be of major importance over the next few years, when entities in Australia, Europe, New Zealand and elsewhere go through the transition to IFRS. This is important for countries that have never had an urgent issues group or an interpretations committee. It is also important for countries that have existing interpretation committees to understand IFRIC processes in order to 'position themselves' in an IASB world. On the other hand, recent reviews and changes to IFRIC processes indicate that the IFRIC interpretation is an evolving process." $\left[{ }^{5}\right]$ O International Accounting Standards Board (IASB) é o orgão normatizador da Contabilidade Internacional. [']Institui normas gerais para licitação e contratação de parceria público-privada no âmbito da administração pública. [ $\left.{ }^{7}\right]$ Dispõe sobre o regime de concessão e permissão da prestação de serviços públicos previsto no art. 175 da Constituição Federal, e dá outras providências.

$\left.{ }^{8}\right]$ Por exemplo, podem ser citadas algumas reportagens sobre o assunto, tais como: PPP é primeira cláusula do novo contrato social, avalia Tarso Genro. Valor Online. 08/12/2003; Comissão aprova texto que regula PPP. Valor Online. Maria Lúcia Delgado. 19/02/2004; Êxito de PPPs depende de regras estáveis. Valor Online. Cândida Vieira. 01/04/2004; As PPPs e os riscos para o investidor privado. Por Antonio Corrêa Meyer e José Virgílio Lopes Enei. 26/03/2004; Para relator, quem construir PPPs deve administrá-las. Ricardo Balthazar. Valor Online.09/11/2004; A aprovação da nova lei das parcerias público-privadas. Valor Online. Por Claudia Elena Bonelli e Rodnei Iazzetta. 06/01/2005; O uso das PPPs e a concessão de rodovias. Valor Online. Por Rodrigo Maluf Barella. 07/06/2005; Setor público pode assumir até 40\% do risco em PPPs. Valor Online. Cristiano Romero e Arnaldo Galvão. 22/08/2006; Regras criam dúvidas sobre retorno previsto para PPP da União. Valor Online. Daniel Rittner. 25/09/2006; PPPs são alternativa para bancar grandes projetos. Roberto Rockmann, para o Valor. 23/11/2006; Primeira PPP do país deve ser executada na cidade de Rio Claro. Valor. Samantha Maia. 22/11/2006; São Paulo amplia estudos para PPPs e tem 6 projetos em pauta. Valor. Samantha Maia. 28/06/2007; Porto Alegre lança PPP para transporte coletivo. Valor. Sérgio Bueno. 28/05/2007. Avançam as PPPs para prisões. Valor. Carolina Mandl e Raquel Salgado. 31/01/2008; Pernambuco lança PPP para construir presídio. Valor. Carolina Mandl. 11/01/2008.
\end{abstract}


$\left[{ }^{9}\right]$ Original: As the worldwide enthusiasm about privatizations waned, PPPs began to boom. One reason governments like PPPs is that they provide a temporary transfer of most of the benefits of ownership of the assets at stake to private firms, thus avoiding criticism from those who oppose privatization. At the same time, because some ownership rights are transferred, governments can also claim that private sector participation is being advanced.

$\left[{ }^{10}\right]$ Original: HM Treasury (2003) estimates that, over the period 1998-9 to 2003-4, private sector investment in public services through PFI was between 10 and $13.5 \%$ of total investment in public infrastructure, with 451 PFI projects completing construction, including 34 hospitals and 119 other health schemes, and 239 new and refurbished schools.

[ $\left.{ }^{11}\right]$ IAS 32, um ativo financeiro é qualquer ativo que seja: (a) dinheiro; (b) um instrumento patrimonial de uma outra entidade; (c) um direito contratual: (i) de receber dinheiro ou outro ativo financeiro de outra entidade;ou (ii) de trocar ativos financeiros ou passivos financeiros com outra entidade em condições que sejam potencialmente favoráveis para a entidade; ou (d) um contrato que será ou poderá ser liquidado nos instrumentos patrimoniais da própria entidade e que seja: (i) um não derivativo para o qual a entidade esteja ou possa estar obrigada a receber um número variável dos instrumentos patrimoniais da própria entidade; ou (ii) um derivativo que será ou poderá ser liquidado de forma diferente da troca de uma quantia fixa em dinheiro ou outro ativo financeiro por um número fixo dos instrumentos de capital próprio da própria entidade. Para esta finalidade, os instrumentos patrimoniais da própria entidade, não incluem instrumentos que sejam eles próprios contratos para futuro recebimento ou entrega dos instrumentos patrimoniais da própria entidade.

$\left[{ }^{12}\right]$ De acordo com a IAS 39 investimentos mantidos até o vencimento são ativos financeiros não derivativos com pagamentos fixos ou determináveis e maturidade que a entidade tem a intenção positiva e capacidade de deter até o vencimento.

$\left[{ }^{13}\right]$ De acordo com o IAS 39, um Derivativo é um Instrumento Financeiro que atende cumulativamente aos três requerimentos: (a) o valor muda em resposta à mudança específica na taxa de juros, preço de títulos e valores mobiliários, preço de commodities, taxa de câmbio, índice ou taxa de preços, rating ou índice de crédito, ou outra variável similar; (b) nenhum ou pouco investimento líquido inicial é requerido, em relação a outros tipos de contratos que tenham resposta similar às mudanças nas condições do mercado; e (c) a liquidação se dará em data futura.

$\left[{ }^{14}\right]$ IAS 38, 45-47. 45 One or more intangible assets may be acquired in exchange for a non-monetary asset or assets, or a combination of monetary and non-monetary assets. The following discussion refers simply to an exchange of one non-monetary asset for another, but it also applies to all exchanges described in the preceding sentence. The cost of such an intangible asset is measured at fair value unless (a) the exchange transaction lacks commercial substance or (b) the fair value of neither the asset received nor the asset given up is reliably measurable. The acquired asset is measured in this way even if an entity cannot immediately derecognise the asset given up. If the acquired asset is not measured at fair value, its cost is measured at the carrying amount of the asset given up. 46 An entity determines whether an exchange transaction has commercial substance by considering the extent to which its future cash flows are expected to change as a result of the transaction. An exchange transaction has commercial substance if: (a) the configuration (ie risk, timing and amount) of the cash flows of the asset received differs from the configuration of the cash flows of the asset transferred; or (b) the entity-specific value of the portion of the entity's operations affected by the transaction changes as a result of the exchange; and (c) the difference in (a) or (b) is significant relative to the fair value of the assets exchanged. For the purpose of determining whether an exchange transaction has commercial substance, the entity-specific value of the portion of the entity's operations affected by the transaction shall reflect post-tax cash flows. The result of these analyses may be clear without an entity having to perform detailed calculations. 47 Paragraph 21(b) specifies that a condition for the recognition of an intangible asset is that the cost of the asset can be measured reliably. The fair value of an intangible asset for which comparable market transactions do not exist is reliably measurable if (a) the variability in the range of reasonable fair value estimates is not significant for that asset or (b) the probabilities of the various estimates within the range can be reasonably assessed and used in estimating fair value. If an entity is able to determine reliably the fair value of either the asset received or the asset given up, then the fair value of the asset given up is used to measure cost unless the fair value of the asset received is more clearly evident.

$\left[{ }^{15}\right] \mathrm{O}$ crédito do contrato deve compreender: (a) a quantia inicial de crédito acordada no contrato; e (b) variações no trabalho, reclamações e pagamentos de incentivos do contrato: (i) até ao ponto que seja provável que resultem em crédito; e (ii) estejam em condições de serem confiavelmente mensurados. O crédito do contrato é medido pelo justo valor da retribuição recebida ou a receber.

$\left[{ }^{16}\right]$ Prestação de serviços. Quando o desfecho de uma transação que envolva a prestação de serviços possa ser estimado com confiabilidade, o crédito associado com a transação deve ser reconhecido com referência à fase de acabamento da transação à data do balanço. O desfecho de uma transação pode ser estimado com confiabilidade quando todas as condições seguintes forem satisfeitas: (a) a quantia de crédito possa ser fiavelmente mensurada; (b) seja provável que os benefícios econômicos associados à transação fluam para a entidade; (c) a fase de acabamento da transação à data do balanço possa ser confiavelmente mensurada; e (d) os custos incorridos com a transação e os custos para concluir a transação possam ser confiavelmente mensurados. $\mathrm{O}$ reconhecimento do crédito com referência à fase de acabamento de uma transação é muitas vezes referido como o método da percentagem de acabamento. Por este método, o crédito é reconhecido nos períodos contábeis em que os serviços sejam prestados. O reconhecimento do crédito nesta base proporciona informação útil sobre a extensão da atividade de serviço e desempenho durante um período. Quando o desfecho da transação que envolva a prestação de serviços não possa ser estimado com confiabilidade, o crédito somente deve ser reconhecido na medida em que sejam recuperáveis os gastos reconhecidos. 